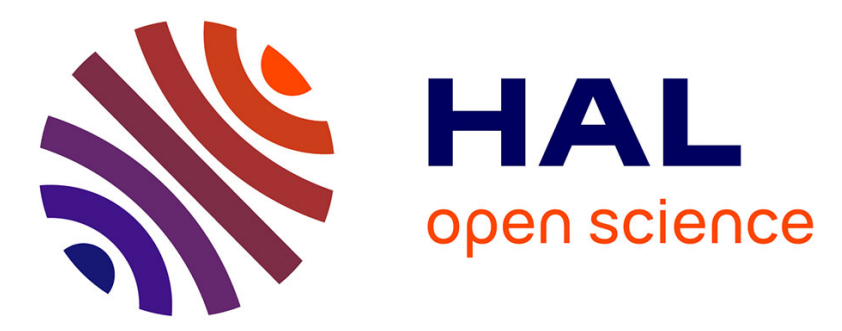

\title{
Analysis of E-Beam Microlithography and SEM Imaging Distortions
}

\author{
Adrien Guery, Félix Latourte, François Hild, Stéphane Roux
}

\section{To cite this version:}

Adrien Guery, Félix Latourte, François Hild, Stéphane Roux. Analysis of E-Beam Microlithography and SEM Imaging Distortions. SEM Annual Conference and Exposition on Experimental and Applied Mechanics, Jun 2014, Greenville, United States. pp.297 - 302, 10.1007/978-3-319-06986-9_33 . hal01088145

\section{HAL Id: hal-01088145 \\ https://hal.science/hal-01088145}

Submitted on 27 Nov 2014

HAL is a multi-disciplinary open access archive for the deposit and dissemination of scientific research documents, whether they are published or not. The documents may come from teaching and research institutions in France or abroad, or from public or private research centers.
L'archive ouverte pluridisciplinaire HAL, est destinée au dépôt et à la diffusion de documents scientifiques de niveau recherche, publiés ou non, émanant des établissements d'enseignement et de recherche français ou étrangers, des laboratoires publics ou privés. 


\title{
ANALYSIS OF E-BEAM MICROLITHOGRAPHY AND SEM IMAGING DISTORTIONS
}

\author{
A. Guery, ${ }^{1,2}$ F. Latourte $^{1}$, F.Hild ${ }^{2}$ and S. Roux ${ }^{2}$ \\ ${ }^{1}$ EDF R\&D, Site des Renardières, Avenue des Renardières - Ecuelles, 77818 Moret-sur-Loing, France \\ ${ }^{2}$ LMT Cachan, ENS Cachan / CNRS UMR 8535 / PRES UniverSud Paris \\ 61 Avenue du Président Wilson, 94235 Cachan Cedex, France \\ Email: adrien.guery@1mt.ens-cachan.fr
}

\begin{abstract}
Surface patterning by e-beam lithography and SEM imaging distortions are studied via digital image correlation. The surface of a stainless steel specimen is marked with a numerically-generated random pattern by microlithography. The global distortions from the reference pattern are first quantified by digital image correlation between the virtual reference pattern and the actual SEM image both in secondary and backscattered electron imaging modes. A second order polynomial basis reveals sufficient to capture most of the distortions. They result from both patterning and imaging techniques. To separate the two contributions without resorting to an external caliper, it is proposed to analyze a series of images of the same patterned surface acquired after rotations of the specimen by different angles. The apparent displacement fields are expressed as a static field, corresponding to the imaging distortion, and another one that rotates together with the specimen. Because large rotations are considered, the problem is nonlinear in the entire set of parameters characterizing each displacement field, but can be solved with an iterative scheme. The obtained patterning distortions appear smaller than those due to imaging on wide field images.
\end{abstract}

Keywords: SEM, microlithography patterning, digital image correlation, patterning distortions, imaging distortions

\section{INTRODUCTION}

Kinematic measurements are performed to study the mechanical behavior of materials. This can be done at the microstructure scale by using a Scanning Electron Microscope (SEM). Such spatially dense experimental information offers a wide scope of possibilities, such as for example the comparison with simulations to identify material parameters [1] associated with crystal plasticity constitutive equations [2]. Yet, the imaging distortions induced by the SEM electromagnetic environment should be taken into account to ensure the accuracy of the experimental information [3].

To perform kinematic measurements using Digital Image Correlation (DIC), a gray level pattern is required on the observed surface of the sample. When the natural texture of the material is not suitable, an artificial one may be deposited onto the surface. In the case of SEM imaging, a common practice is to resort to microgrid marking using e-beam microlithography [4]. In this study, the same marking technique is employed, but has been tailored to create a numerically-generated random speckle, which presents the advantage (for DIC) to not induce spatially periodic patterns. Global distortions between the theoretical (or "reference") pattern and its SEM image, resulting from patterning and imaging, are measured by DIC. A partition method of these two contributions is performed using several SEM images of the pattern after a set of rotations of the sample in the SEM.

\section{GLOBAL DISTORTIONS MEASUREMENT BY DIGITAL IMAGE CORRELATION}

A gold speckle is deposited onto the surface of an in-situ specimen by a process of microlithography patterning. The material is $316 \mathrm{LN}$ austenitic stainless steel. The surface is prepared by mechanical polishing with colloidal silica finish. The process is divided into five main steps (see Figure 1). The principle consists of exposing a resist film, deposited onto the surface, with 
the electron beam of the SEM only at specific positions following a pattern design. For that purpose, a Raith Elphy Quantum commercial system is used to control the FEI Quanta FEG 600 SEM. After the dissolution of the exposed resist, a very thin layer of gold is deposited over the entire surface, and a final dissolution step of the resist film leaves gold only in the region that were first swept by the e-beam. In the present case, the speckle pattern is chosen to be a known distribution of diskshaped spots of random radius and position.

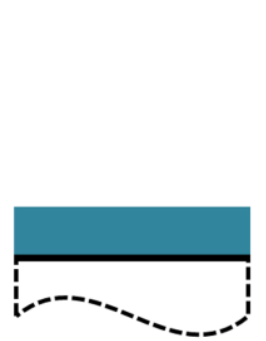

(a)

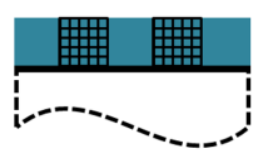

(b)

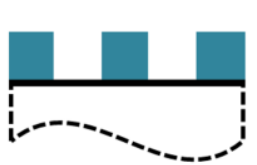

(c)

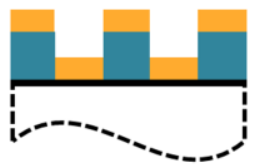

(d)
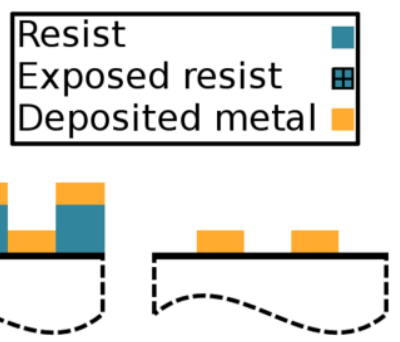

(e)

Fig. 1: Surface gold patterning using e-beam microlithography: resin film deposition (a), electron beam exposure (b), exposed resist film development (c), gold deposition (d), residual resist film dissolution (e)

The speckle covers a $400 \mu \mathrm{m}$ side square surface. Figure 2 (a) shows an SEM image of the imaged gold pattern using backscattered electron (BSE) detector at a working distance of $14 \mathrm{~mm}$, with an acceleration voltage of $10 \mathrm{kV}$. Images are acquired with a physical size of $240 \mathrm{~nm}$ per pixel and stored in 16 bit format. Thanks to the histogram of gray levels of the SEM image, a reference image of the known distribution of spots is built. Its background is set as a homogeneous gray level read at the peak of the histogram corresponding to the uncovered alloy. Spots are set as a Gaussian-shaped distribution of gray levels whose mean value is read at the peak of the histogram related to the gold disks. Because the underlying microstructure of the material involves different gray levels (see Figure 2(a)), this process is performed regionally after a simple first segmentation of the main regions. Figure 2 (b) shows the reference image obtained from the SEM image in Figure 2 (a).

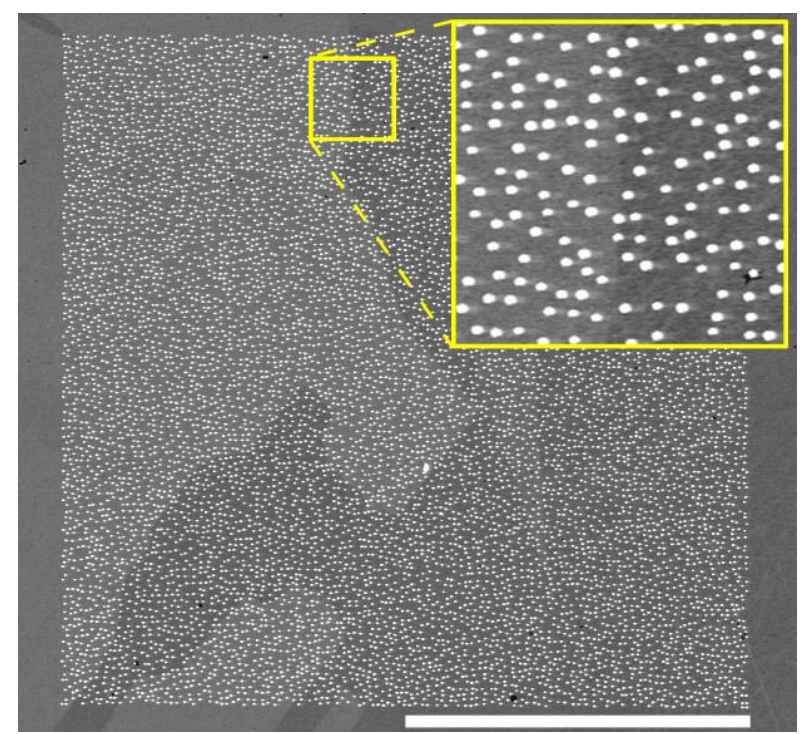

(a)

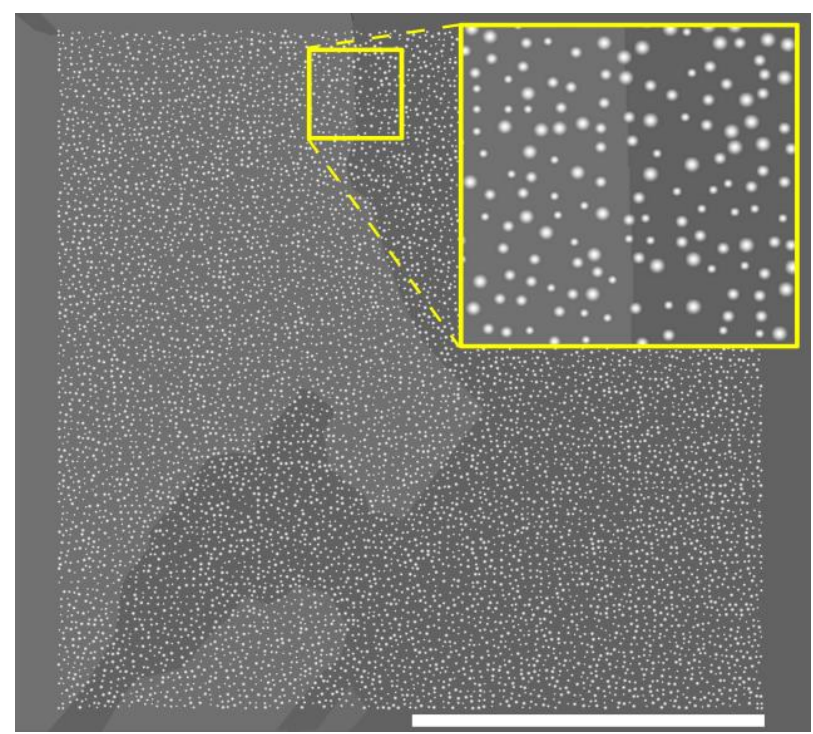

(b)

Fig. 2: SEM image of the gold pattern using BSE detector (a), and corresponding reference image generated numerically (b). The scale bar is $200 \mu \mathrm{m}$

The displacement fields between the SEM image, denoted $f$, and the computer-generated image, $g$, of the pattern are measured using finite element based DIC [5], which is based on the conservation of the texture 


$$
f(\mathbf{z})=g(\mathbf{z}+\mathbf{u}(\mathbf{z}))
$$

where $\mathbf{z}$ is the complex-valued coordinates of pixels in $f$, and $\mathbf{u}$ the sought displacement field. The minimization of the gray level residuals leads to the iterative solution of linear systems [6]

$$
[\mathbf{M}]\{\delta \mathbf{u}\}=\{\mathbf{s}\}
$$

with

$$
M_{i j}=\sum_{R O I}\left(\boldsymbol{\psi}_{i} \cdot \nabla f\right)(\mathbf{z})\left(\boldsymbol{\psi}_{j} \cdot \nabla f\right)(\mathbf{z})
$$

and

$$
s_{i}=\sum_{R O I}(f-\tilde{g})(\mathbf{z})\left(\boldsymbol{\Psi}_{i} \cdot \nabla f\right)(\mathbf{z})
$$

where, at each iteration, $\{\delta \mathbf{u}\}$ is a vector of the displacement corrections, and $\tilde{g}$ the deformed image corrected by the current estimation of the displacement field. $\boldsymbol{\psi}_{i}$ are chosen basis functions for the displacement discretization, in the present case an unstructured mesh of 3-noded triangular elements (about 40 pixel / $9.6 \mu \mathrm{m}$ sides). With this DIC technique, a Root Mean Square (RMS) value of the displacement uncertainty of 0.02 pixel $($ or $5.0 \mathrm{~nm}$ ) is measured (between 2 SEM images with no motion).

In addition to rigid body motions, the obtained field includes distortions resulting from both patterning and imaging errors. The separation of these two contributions is not reachable so far.

\section{PARTITION OF DISTORTIONS}

A partition method of global distortions between patterning and imaging distortions is now presented. A set of ten rotations of an angle $\theta^{k}$ ranging from $0^{\circ}$ to $90^{\circ}$ of the observed pattern is applied inside the SEM chamber (via the stage rotation) prior to imaging. Displacement fields, denoted $\mathbf{u}^{k}$, are then measured using DIC between the acquired images and the reference image of the pattern. Because large rotations are prescribed, the previous DIC formulation has been adapted considering finite transformation kinematics [7]. The partition method consists of considering each displacement field $\mathbf{u}^{k}$ as a composition of three transformations, namely, a patterning distortions field $\mathbf{v}_{\mathrm{g}}$, identical for each $\mathbf{u}^{\mathrm{k}}$, a rotation of an angle $\theta^{k}$, and an imaging distortions field $\boldsymbol{v}_{\mathrm{d}}$, assumed to be time-independent. This procedure is described in Figure 3.

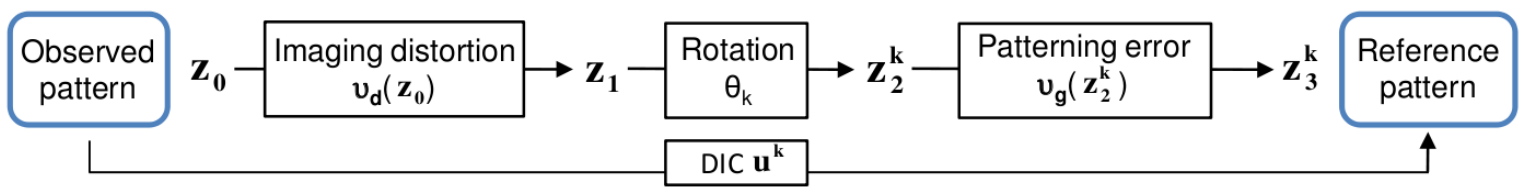

Fig. 3: Schematic of the partition of each of the $k$ measurements of global distortions

The two unknown distortion fields are chosen to be described as a linear combination of polynomials expressed in the complex plane as

$$
\mathbf{d}_{k l}(\mathbf{z})=\mathbf{z}^{k} \overline{\mathbf{z}}^{l} \text { with } 0 \leq k, 0 \leq l, k+l \leq p
$$

where $\overline{\mathbf{z}}$ denotes the conjugate of $\mathbf{z}$, and $p$ the order of the series. Analytical expressions generally proposed in the literature [8] are described via this chosen basis too. A second order expansion of this polynomial basis appeared sufficient to describe both patterning and imaging distortions fields. Thus, $\left(a_{1}^{d}, \ldots, a_{6}^{d}\right)$ and $\left(a_{1}^{g}, \ldots, a_{6}^{g}\right)$ denote the unknown complex-valued coefficients of the polynomial series describing $\boldsymbol{v}_{\mathrm{d}}$, respectively $\boldsymbol{v}_{\mathrm{g}}$.

For each of the $k$ displacement measurements, the deformed coordinate system in the reference image is given by 


$$
\mathbf{z}_{3}^{k}=\mathbf{z}_{0}+\mathbf{u}^{k}\left(\mathbf{z}_{0}\right)
$$

With the proposed partition method, an approximation of $\mathbf{z}_{3}^{k}$, denoted $\hat{\mathbf{z}}_{3}^{k}$, is proposed as

$$
\hat{\mathbf{z}}_{3}^{k}=\left(\mathbf{z}_{0}+\mathbf{v}_{d}\left(\mathbf{z}_{0}, a_{1}^{d}, \ldots, a_{6}^{d}\right)\right) e^{i \theta^{k}}+\mathbf{v}_{g}\left(\hat{\mathbf{z}}_{2}^{k}, a_{1}^{g}, \ldots, a_{6}^{g}\right)
$$

with

$$
\hat{\mathbf{z}}_{2}^{k}=\left(\mathbf{z}_{0}+\mathbf{v}_{d}\left(\mathbf{z}_{0}, a_{1}^{d}, \ldots, a_{6}^{d}\right)\right) e^{i \theta^{k}}
$$

The error fields are then expressed as

$$
\mathbf{r}^{k}=\mathbf{z}_{3}^{k}-\hat{\mathbf{z}}_{3}^{k}
$$

These fields are minimized in a weighted least squares criterion with respect to the sought coefficients $\left(a_{1}^{d}, \ldots, a_{6}^{d}\right)$ and $\left(a_{1}^{g}, \ldots, a_{6}^{g}\right)$

$$
\left(a_{1}^{d}, \ldots, a_{6}^{d}, a_{1}^{g}, \ldots, a_{6}^{g}\right)=\arg \min \left(\sum_{k}\left\{\mathbf{r}^{k}\right)\left[\mathbf{M}^{k}\right]\left(\mathbf{r}^{k}\right\}\right)
$$

where $\left[\mathbf{M}^{k}\right]$ is the DIC matrix associated to the measured degrees of freedom of $\mathbf{u}^{k}$, which is shown to be proportional to the inverse of the covariance matrix of measured degrees of freedom [6], and therefore appears adequate to weight the error fields in the least squares criterion.

The problem is nonlinear because of large rotations. However, it becomes linear if considering one of the functions $\mathbf{v}_{\mathrm{d}}$ or $\mathbf{v}_{\mathrm{g}}$ as known, and the other one is sought, and vice-versa. A few iterations are needed for converging to a minimum of the residual function. Figure 4 shows the change of the RMS error fields $\mathbf{r}^{k}$ as a function of the measured rotation angle of the pattern between the first and the last iteration.

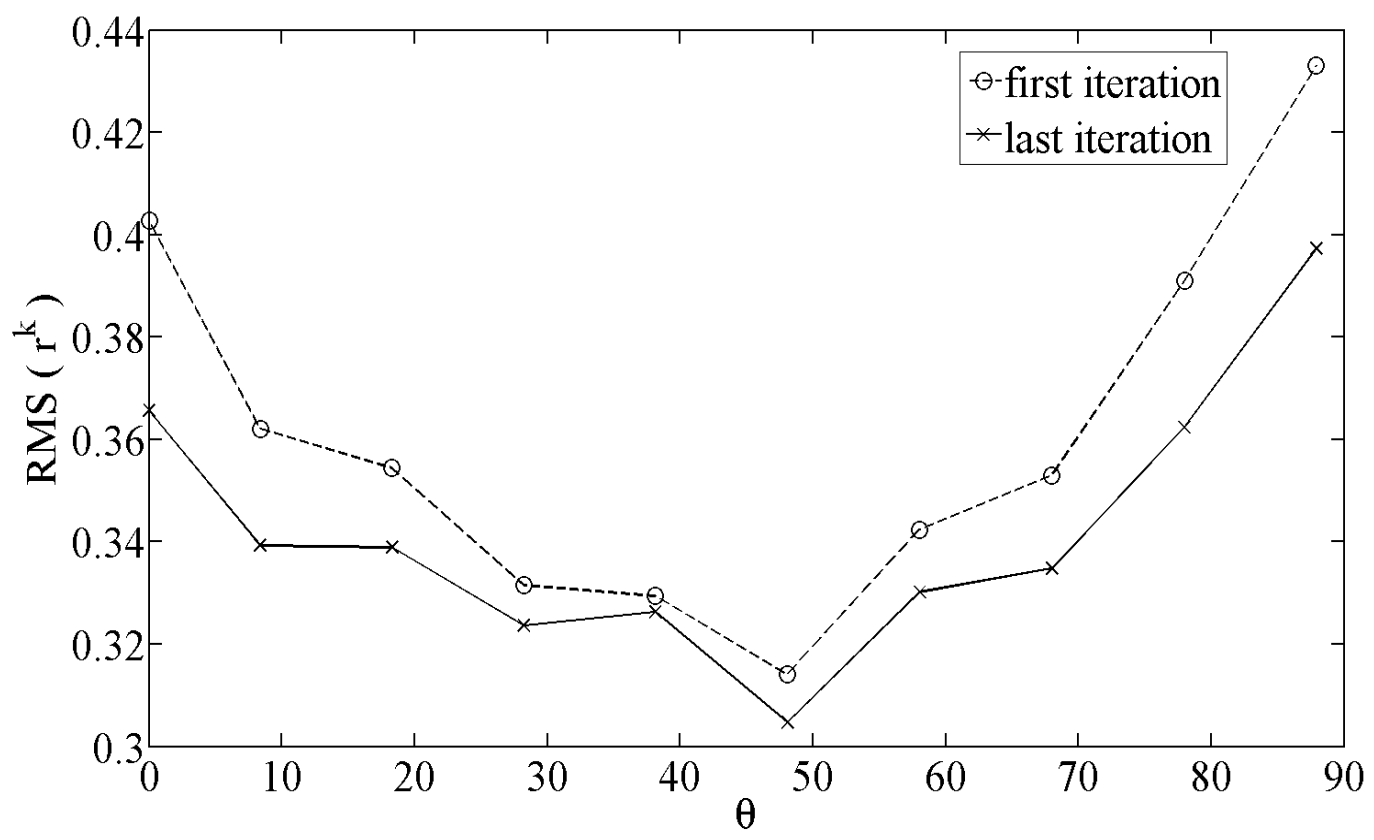

Fig. 4: RMS value of the error fields expressed in pixels as a function of the measured rotation angle of the pattern in degrees. The physical size of one pixel is $240 \mathrm{~nm}$ 
Obtained imaging distortions and patterning errors at convergence are shown in Figure 5. Note that, in this figure, the element of the polynomial series describing magnification changes (i.e., $\mathbf{d}_{10}(\mathbf{z})=\mathbf{z}$, with a real amplitude) is not considered. Its amplitude is due to small magnification changes between the SEM image and the reference picture. Electron beam microlithography appears to involve smaller errors (in the $400 \mathrm{~nm}$ range) than SEM imaging does (in the $600 \mathrm{~nm}$ range). The imaging distortion magnitude is less than that observed by Sutton et al [3] (of the order of $2.5 \mu \mathrm{m}$ ) but at a magnification about two times lower, and with a (very) different SEM. Moreover, the maximum levels of patterning errors are reached at the edges of the area of interest, which is consistent with the second step of the patterning process. The exposure of each elementary pattern (circular disks) is performed by electron beam deflection from the center of the square surface to mark, and thus it is expected to be less accurate far from the center. Last, the same experiment has been conducted with twice the previous magnification with a $100 \mu \mathrm{m}$ side square speckle and very similar results have been obtained.

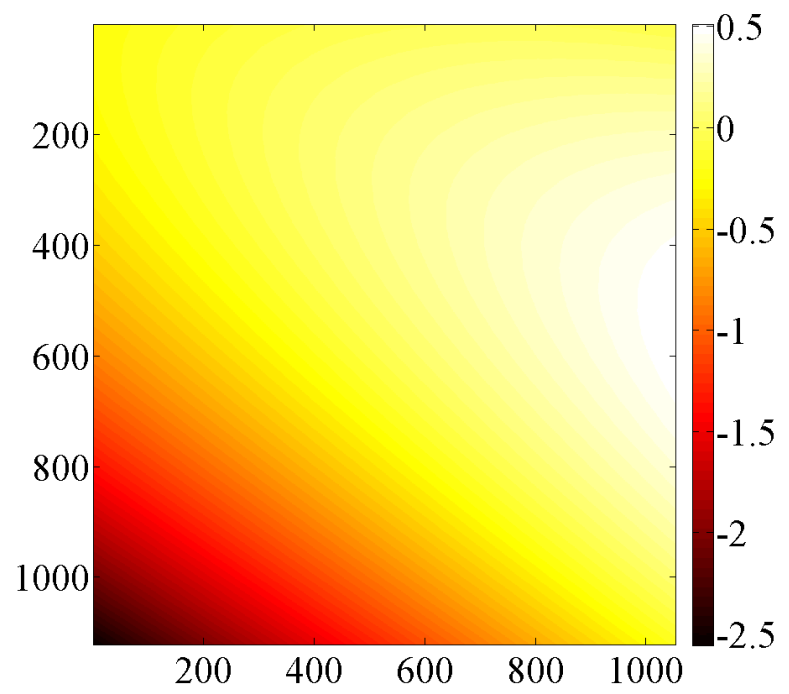

(a)

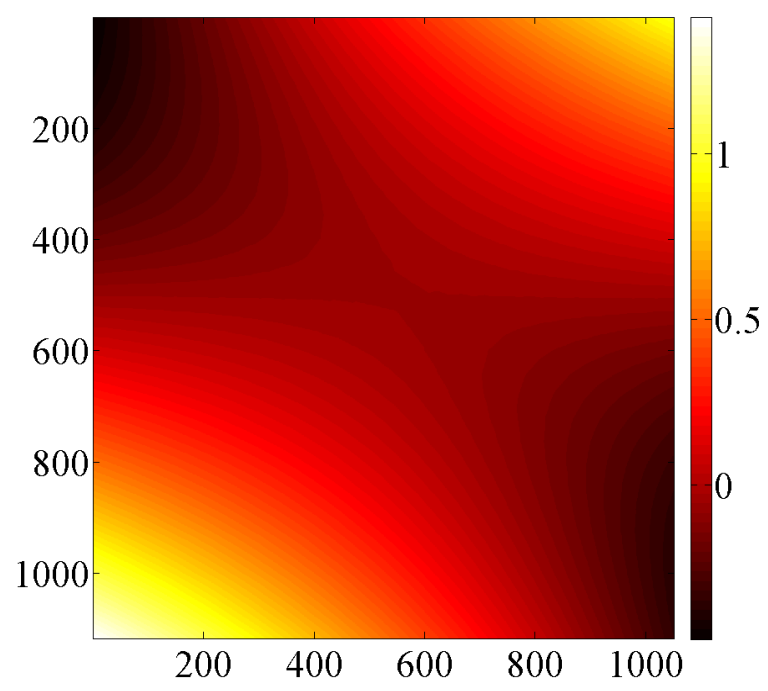

(c)

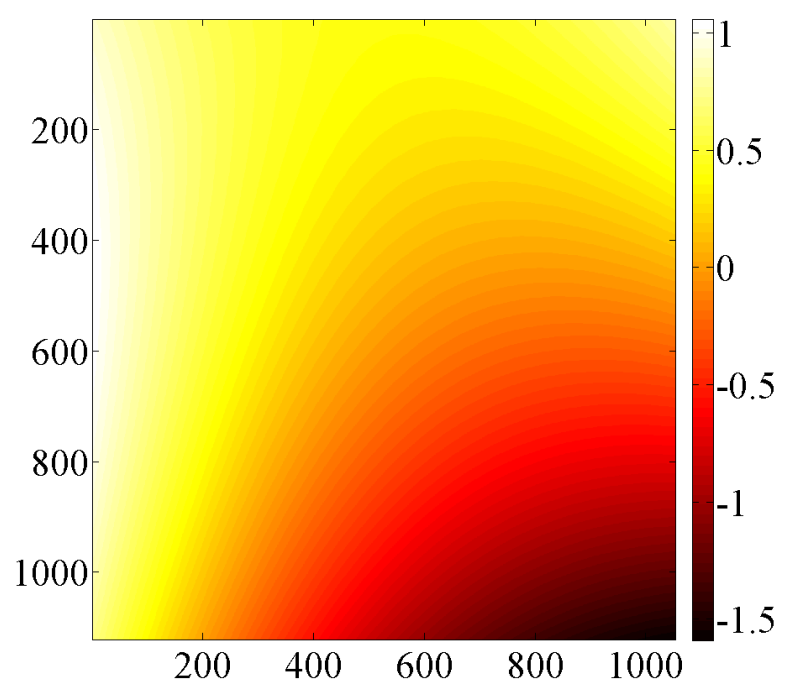

(b)

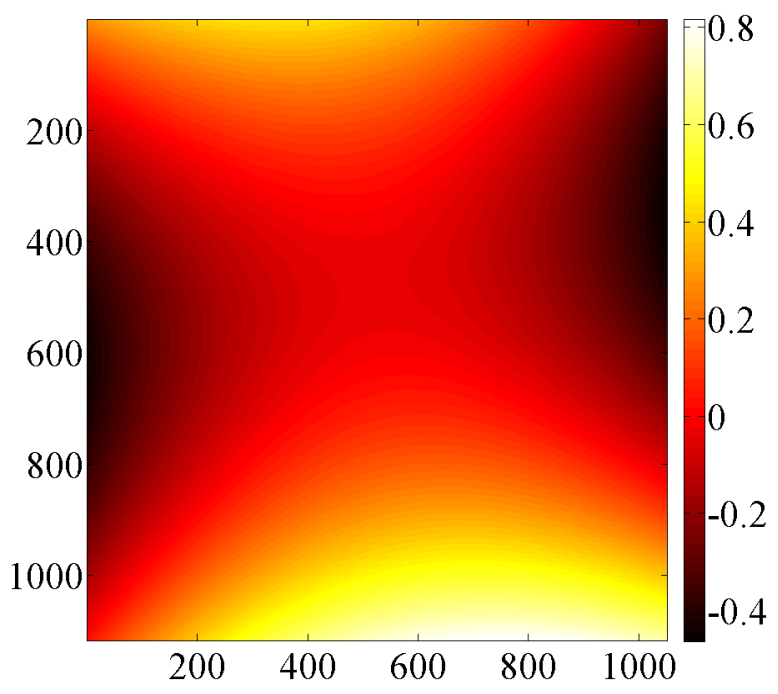

(d)

Fig. 5: Horizontal (a) and vertical (b) components of imaging distortions. Horizontal (c) and vertical (d) components of patterning errors. The fields are expressed in pixels, whose physical size is $240 \mathrm{~nm}$ 


\section{CONCLUSIONS}

A gold patterning process has been introduced to mark stainless steel surfaces with a numerically-generated random pattern using microlithography. Global distortions have been quantified using digital image correlation between an SEM image of the pattern and its corresponding reference image, including both patterning and SEM imaging biases. It has then been shown that it is possible to separate these two contributions by collecting several evaluations of this global distortion with various angles of rotation of the observed pattern. The patterning has been shown to involve lower errors than SEM imaging distortions. From these analyses, it would be relevant to check for any additional drifts due to SEM environment too. The subsequent use of SEM images for kinematic measurements requires a good characterization and quantification of the measurement errors.

\section{REFERENCES}

[1] Héripré E., Dexet M., Crépin J., Gélébart L., Roos A., Bornert M., and Caldemaison D., Coupling between experimental measurements and polycrystal finite element calculations for micromechanical study of metallic materials. International Journal of Plasticity, 23(9), 1512-1539, 2007.

[2] Roters F., Eisenlohr P., Hantcherli L.,Tjahjanto D.D., Bieler T.R., and Raabe D., Overview of constitutive laws, kinematics, homogenization and multiscale methods in crystal plasticity finite-element modeling: Theroy, experiments, applications, Acta Materialia, 58, 1152-1211, 2010.

[3] Sutton M.A., Li N., Garcia D., Cornille N., Orteu J.J., McNeill S.R., Schreier H.W., and Li X., Metrology in a scanning electron microscope: theoretical developments and experimental validation, Measurement Science and Technology, 17, 2613-2622, 2006.

[4] Allais A., Bornert M., Bretheau T., and Caldemaison D., Experimental characterization of the local strain field in an heterogeneous elastoplastic material, Axta Metalurgica Materialia, 42(11), 3865-3880, 1994.

[5] Leclerc H., Périé J.-N., Roux S., and Hild F., Integrated digital image correlation for the identification of mechanical properties, MIRAGE 2009, LNCS, 5496, 161-171, 2009.

[6] Besnard G., Hild F., and Roux S., "Finite-Element" displacement fields analysis from digital images: Application to portevin-le chatelier bands, Experimental Mechanics, 46(6), 789-803, 2006.

[7] Guery A., Latourte F., Hild F., and Roux S., Characterization of SEM speckle pattern marking and imaging distortion by digital image correlation, Measurement Science and Technology, 25, 12pp, 2014.

[8] Sutton M.A., Orteu J.J., and Schreier H.W., Image correlation for shape, motion and deformation measurements: basic concepts, theory and application, Springer handbook of experimental solid mechanics, Berlin, 2009. 